\title{
Randomized Evidence for Reduction of Perioperative Mortality: An Updated Consensus Process
}

Giovanni Landoni, MD, ${ }^{*}+$ Antonio Pisano MD, $\neq$ Vladimir Lomivorotov, MD, PhD, $\S$ Gabriele Alvaro, MD, $\|$ Ludhmila Hajjar, MD, I Gianluca Paternoster, MD, ${ }^{*}$ Caetano Nigro Neto, MD, PhD, ** Nicola Latronico, MD, ††

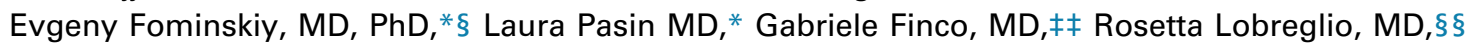

Maria Luisa Azzolini, MD,* Giuseppe Buscaglia, MD, \|\| Alberto Castella, MD,* Marco Comis, MD, III

Adele Conte, MD, $\neq$ Massimiliano Conte, MD, ${ }^{\# \#}$ Francesco Corradi, MD,*** Erika Dal Checco, MD, †††

Giovanni De Vuono, MD, || Marco Ganzaroli, MD, III Eugenio Garofalo, MD, || Gordana Gazivoda, MD, $\neq \neq \neq$

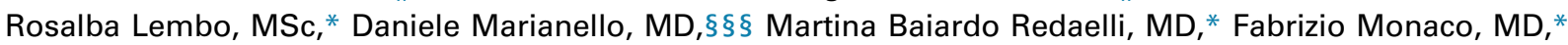
Valentina Tarzia, MD,* Marta Mucchetti, MD,* Alessandro Belletti, MD,* Paolo Mura, MD, $\neq \neq$ Mario Musu, MD, $\neq \neq$

Giovanni Pala, MD, || ||| Massimiliano Paltenghi, MD,†† Vadim Pasyuga, MD, IIIII Desiderio Piras, MD, $\neq \ddagger$

Claudio Riefolo, DS, * Agostino Roasio, MD, ${ }^{\# \# ~ L a u r a ~ R u g g e r i, ~ M D, * ~ F r a n c e s c o ~ S a n t i n i, ~ M D, * * * * ~}$

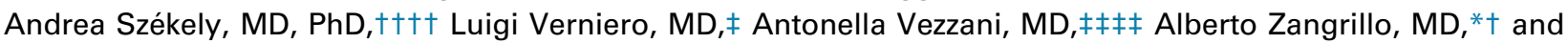

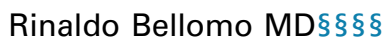

Objective: Of the 230 million patients undergoing major surgical procedures every year, more than 1 million will die within $\mathbf{3 0}$ days. Thus, any nonsurgical interventions that help reduce perioperative mortality might save thousands of lives. The authors have updated a previous consensus process to identify all the nonsurgical interventions, supported by randomized evidence, that may help reduce perioperative mortality.

Design and Setting: A web-based international consensus conference.

Participants: The study comprised 500 clinicians from 61 countries.
Interventions: A systematic literature search was performed to identify published literature about nonsurgical interventions, supported by randomized evidence, showing a statistically significant impact on mortality. A consensus conference of experts discussed eligible papers. The interventions identified by the conference then were submitted to colleagues worldwide through a web-based survey.

Measurements and Main Results: The authors identified 11 interventions contributing to increased survival (perioperative hemodynamic optimization, neuraxial anesthesia, noninvasive ventilation, tranexamic acid, selective

From the *Department of Anesthesia and Intensive Care, IRCCS San Raffaele Scientific Institute, Milan, Italy; †Vita-Salute San Raffaele University, Milan, Italy; †Division of Cardiac Anaesthesia and Intensive Care, Azienda Ospedaliera Dei Colli, Monaldi Hospital, Naples, Italy; §Department of Anaesthesia and Intensive Care, Academician EN Meshalkin Novosibirsk State Budget Research Institute of Circulation Pathology, Novosibirsk, Russia; \|Department of Anaesthesia and Intensive Care, Azienda Ospedaliera Universitaria "Mater Domini," Catanzaro, Italy; IIDisciplina de Anestesia, Incor-Hospital das Clinicas, Sao Paulo, Brazil; \#Department of Cardiovascular Anaesthesia and Intensive Care, Ospedale San Carlo, Potenza, Italy; **Dante Pazzanese Institute of Cardiology, Department of Anesthesia and Intensive Care, Sao Paulo, Brazil; †Department of Anaesthesia and Intensive Care, Spedali Civili, Brescia, Italy; \$Anesthesia and Intensive Care Unit, Policlinico "Duilio Casula" AOU Cagliari, Department of Medical Sciences “M. Aresu," Cagliari, Italy; \$\$Department of Cardiac Anaesthesia and Intensive Care, San Giovanni Battista Hospital, University of Turin, Turin, Italy; || ||Department of Cardiac Anaesthesia and Intensive Care, IRCCS University Hospital San Martino IST, Genova, Italy; IIIICardiac and Vascular Department, Ospedale Mauriziano Umberto I, Torino, Italy; \#\#Department of Anesthesia and Intensive Care, Mater Dei Hospital, Bari, Italy; ***Department of Anaesthesia and Intensive Care, Ente Ospedaliero Ospedali Galliera, Genova, Italy; †+Department of Cardiothoracic and Vascular Anaesthesia and Intensive Care, Università degli Studi di Bologna-Azienda Ospedaliera Sant'Orsola-Malpighi, Bologna, Italy; +tDepartment of Anaesthesia and Intensive Care, Institute of Cardiovascular Diseases Dedinje, Belgrade, Serbia; \$\$\$Department of Thoracic and Cardiac Surgery, University of Siena, Siena, Italy; ||||||Department of Cardioanesthesia and Intensive Care, Ospedale Civile Santissima Annunziata, Sassari, Italy; IIIIICardiac Anaesthesia and Intensive Care, Federal Centre for Cardiac Surgery, Astrakhan, Russia; \#\#\#Department of Anaesthesia and Intensive Care, Ospedale Cardinal Massaia di Asti, Asti, Italy; ****Division of Cardiac Surgery, IRCCS University Hospital San Martino IST, Genova, Italy; $+\dagger+$ Department of Anaesthesiology and Intensive Care, Semmelweis Egyetem, Budapest, Hungary; Dipartimento Cardio-Nefro-Polmonare, Sezione Terapia Intensiva Cardiochirurgica, Azienda Ospedaliero Universitaria di Parma, Parma, Italy; and \$§§§ntensive Care; Austin Hospital, Melbourne, Australia.

G.L. received speaker fees from Abbvie, Orion, Pall, Tenax; V.L. received speaking honoraria from Orion; N.L. received speaker fees from Angelini, Fidia Farmaceutici, Orion, MSD ITALIA, Fondazione Giovanni Lorenzini.

Address reprint requests to Giovanni Landoni, MD, Department of Anaesthesia and Intensive Care, IRCCS San Raffaele Scientific Institute, Via Olgettina, 60 - 20132 - Milan, Italy.E-mail: landoni.giovanni@hsr.it

(C) 2016 Elsevier Inc. All rights reserved. $1053-0770 / 2601-0001 \$ 36.00 / 0$

http://dx.doi.org/10.1053/j.jvca.2016.07.017

Key Words: perioperative care, mortality, consensus, anesthesia, intensive care 
decontamination of the gastrointestinal tract, insulin for tight glycemic control, preoperative intra-aortic balloon pump, leuko-depleted red blood cells transfusion, levosimendan, volatile agents, and remote ischemic preconditioning) and 2 interventions showing increased mortality (beta-blocker therapy and aprotinin). Interventions then were voted on by participating clinicians. Percentages of agreement among clinicians in different countries differed significantly for 6 interventions, and

A LL SURGICAL PROCEDURES are associated with a certain risk of both intraoperative and postoperative adverse events that in some cases can be fatal. However, perioperative mortality generally is perceived as relatively low, especially at individual center level and for elective noncardiac surgery in patients without particular risk profiles. Overall allcause mortality after noncardiac surgery has been reported to be $1 \%$ to $4 \%{ }^{1}$ Moreover, due to the relatively low mortality rate and the complexity of the clinical setting, it is not easy to investigate the impact of therapeutic interventions, which could have significant, though small, effects on perioperative mortality. Accordingly, this matter has never received great attention in the medical literature. ${ }^{2}$ However, of the more than 230 million patients who undergo major surgical procedures worldwide every year, more than 1 million die within 30 days. ${ }^{3}$ Thus, even small reductions in perioperative mortality may save many lives.

To achieve a comprehensive view of this issue and to better understand which drugs, techniques, or strategies should be used (or avoided) by clinicians in an effort to reduce mortality, large collaborative research projects are required and a systematic and effective identification of the interventions that potentially may affect mortality is vital.

Since 2010, the authors have developed an innovative approach to consensus that allowed them to accomplish a comprehensive and widely agreed upon overview of interventions that might affect mortality in different clinical settings, including the perioperative period of any surgical procedure, cardiac surgery, critically ill patients, and acute kidney injury. ${ }^{4-8}$ Because evidence seems to be evolving constantly and rapidly, the authors conducted an update of a previous consensus process on ancillary (nonsurgical) interventions (drugs/techniques/ strategies) that have been shown by at least 1 randomized controlled trial (RCT) or meta-analysis of RCTs to affect perioperative mortality in any adult surgical setting. In addition to a systematic literature search, consensus meeting, and webbased survey about the agreement on the included interventions, the authors investigated the reported use of such interventions in clinical practice and the possible gap between literature evidence and clinical practice. Furthermore, comparison with the previous consensus process gave the opportunity to appreciate how rapidly evidence has evolved.

\section{METHODS}

A systematic MEDLINE/PubMed, Scopus, and Embase search with no time limits that was updated March 6, 2015, was performed by 4 experienced investigators (GL, AP, AB, LR) to identify all of the published literature with randomized evidence of mortality reduction or increase in the perioperative period (see Appendix 1 for the full search strategy). The a variable gap between evidence and clinical practice was noted.

Conclusions: The authors identified 13 nonsurgical interventions that may decrease or increase perioperative mortality, with variable agreement by clinicians. Such interventions may be optimal candidates for investigation in high-quality trials and discussion in international guidelines to reduce perioperative mortality.

(c) 2016 Elsevier Inc. All rights reserved.

authors found additional articles through a cross-check of references and suggestions by experts in the field of perioperative medicine. A website allowed participants worldwide to vote in support of or against the nominated interventions and to submit comments or to report additional articles for inclusion until the day of the consensus meeting.

Only the studies that satisfied all the following criteria were considered: (1) publication in a peer-reviewed journal, (2) assessment of a nonsurgical intervention (drug/technique/strategy) in adult patients undergoing any type of surgery, (3) achievement of a statistically significant reduction or increase in mortality, and (4) conducted as randomized trial or metaanalysis of RCTs.

The in-person meeting was held March 6, 2015, at the VitaSalute University, Milan, Italy, and involved anesthesiologists, intensive care specialists, cardiologists, surgeons, and epidemiologists. During this face-to-face consensus conference, for each intervention, participants were asked to decide whether (1) the most recent evidence had been collected, (2) the effect on mortality was supported by RCTs or meta-analyses of RCTs, (3) the supporting evidence was derived from a primary or a subgroup analysis, (4) the evidence was derived entirely or partially from a surgical population, (5) the intervention was applicable to all patients or to subgroups only, and (6) mortality was the study endpoint or was included in a composite endpoint.

Each intervention was presented by a rapporteur and commented on by 1 or 2 discussants; the consensus process involved the international cohort of participants who voted on the interventions before and after the Milan meeting. A position statement was approved describing the reasons for the inclusion. The studies or interventions that did not meet the aforementioned criteria became major exclusions, and reasons for exclusion were detailed (Tables S1 and S2).

The final interventions and their statements were presented online at the website www.democracybasedmedicine.org (Table 1). Participants worldwide had the opportunity, through the web survey, to support or challenge the interventions and statements from the meeting for the 5 months between March and August 2015. The following 3 questions were asked: (1) Do you agree with this sentence? (Yes/No/Do not know); (2) Do you routinely use this intervention in your clinical practice? (Yes/No/Does not apply); (3) Would you include this intervention into future international guidelines to reduce perioperative mortality? (Yes/No/Do not know)

For the interventions increasing mortality, the second and third questions were asked in an opposite fashion: Do you routinely avoid this intervention in your clinical practice? Would you suggest that future international guidelines should contraindicate 
Table 1. Topics (Drugs and/or Nonsurgical Techniques or Strategies) With Randomized Published Evidence of a Reduction/Increase in Perioperative Mortality

\begin{tabular}{|c|c|c|}
\hline Topics & Sentences & Agreement \\
\hline \multicolumn{3}{|l|}{ Increasing survival } \\
\hline $\begin{array}{l}\text { Perioperative hemodynamic } \\
\text { optimization }\end{array}$ & $\begin{array}{l}\text { According to } 5 \text { meta-analyses of RCTs, perioperative hemodynamic optimization can reduce } \\
\text { mortality in high-risk surgical patients. Uncertainty remains about which invasive devices and/or } \\
\text { therapeutic interventions are to be preferred. This topic merits further investigation. } \\
\text { Do you agree with the above sentence? }\end{array}$ & $95 \%$ \\
\hline Insulin glycemic control & $\begin{array}{l}\text { According to } 2 \text { RCTs and } 1 \text { meta-analysis of RCTs, continuous insulin infusion can reduce } \\
\text { perioperative mortality. The ideal glycemic target is still to be determined and might change in } \\
\text { different settings. The authors strongly recommend caution when using tight glycemic control } \\
\text { because of the risk of hypoglycemic episodes. This topic merits further investigation. } \\
\text { Do you agree with the above sentence? }\end{array}$ & $88 \%$ \\
\hline Noninvasive ventilation & $\begin{array}{l}\text { According to } 3 \text { small RCTs, noninvasive ventilation reduces mortality in acute respiratory failure after } \\
\text { solid organ transplantation, lung resection, and cardiac surgery. This topic merits further } \\
\text { investigation. } \\
\text { Do you agree with the above sentence? }\end{array}$ & $88 \%$ \\
\hline Levosimendan & $\begin{array}{l}\text { According to } 1 \text { small RCT and } 4 \text { meta-analyses of RCTs, levosimendan may reduce } 30 \text {-day mortality } \\
\text { in patients with low ejection fraction undergoing cardiac surgery. This topic merits further } \\
\text { investigation. } \\
\text { Do you agree with the above sentence? }\end{array}$ & $88 \%$ \\
\hline $\begin{array}{l}\text { Leuko-depleted red blood } \\
\text { cells transfusion }\end{array}$ & $\begin{array}{l}\text { According to } 2 \text { RCTs, patients undergoing cardiac surgery might benefit from leukocyte depletion of } \\
\text { transfused blood by filtration. This topic merits further investigation. } \\
\text { Do you agree with the above sentence? }\end{array}$ & $86 \%$ \\
\hline Preoperative IABP & $\begin{array}{l}\text { According to } 1 \text { small RCT and } 4 \text { meta-analyses of RCTs, preoperative IABP can have a beneficial } \\
\text { effect on mortality in specific high-risk patient groups undergoing CABG. This topic merits further } \\
\text { investigation. } \\
\text { Do you agree with the above sentence? }\end{array}$ & $85 \%$ \\
\hline Volatile agents & $\begin{array}{l}\text { According to } 2 \text { meta-analyses of RCTs, volatile anesthetics might reduce } 30 \text {-day mortality in patients } \\
\text { undergoing coronary artery bypass graft surgery. This topic merits further investigation. } \\
\text { Do you agree with the above sentence? }\end{array}$ & $85 \%$ \\
\hline Tranexamic acid & $\begin{array}{l}\text { According to } 1 \text { meta-analysis of RCTs, low-dose tranexamic acid may reduce mortality. This topic } \\
\text { merits further investigation. } \\
\text { Do you agree with the above sentence? }\end{array}$ & $84 \%$ \\
\hline Neuraxial anesthesia & $\begin{array}{l}\text { According to } 4 \text { meta-analyses of RCTs, neuraxial anesthesia may reduce short-term mortality } \\
\text { compared with general anesthesia in noncardiac surgery. This topic merits further investigation. } \\
\text { Do you agree with the above sentence? }\end{array}$ & $81 \%$ \\
\hline $\begin{array}{l}\text { Remote ischemic } \\
\text { preconditioning }\end{array}$ & $\begin{array}{l}\text { According to } 1 \mathrm{RCT} \text {, remote ischemic preconditioning provides perioperative myocardial protection } \\
\text { and might improve late survival in patients undergoing elective coronary artery bypass grafting } \\
\text { surgery. This topic merits further investigation. } \\
\text { Do you agree with the above sentence? }\end{array}$ & $80 \%$ \\
\hline $\begin{array}{l}\text { Selective decontamination } \\
\text { of digestive tract }\end{array}$ & $\begin{array}{l}\text { According to } 1 \text { meta-analysis of RCTs, selective decontamination of the digestive tract in critically ill } \\
\text { surgical patients might reduce mortality. This topic merits further investigation. } \\
\text { Do you agree with the above sentence? }\end{array}$ & $67 \%$ \\
\hline Increasing mortality & & \\
\hline Beta-blockers & $\begin{array}{l}\text { According to } 1 \text { large RCT and } 3 \text { meta-analyses, beta-blockers started immediately before noncardiac } \\
\text { surgery can increase perioperative mortality in patients with, or at risk for, atherosclerotic disease. } \\
\text { Nonetheless, the consensus conference recommends to maintain chronic beta-blocker therapy in } \\
\text { the perioperative period. } \\
\text { Do you agree with the above sentence? }\end{array}$ & $83 \%$ \\
\hline Aprotinin & $\begin{array}{l}\text { According to } 1 \mathrm{RCT} \text {, aprotinin increases } 30 \text {-day mortality in adult patients undergoing cardiac } \\
\text { surgery. } \\
\text { Do you agree with the above sentence? }\end{array}$ & $73 \%$ \\
\hline
\end{tabular}

Abbreviations: $C A B G$, coronary artery bypass grafting; IABP, intra-aortic balloon pump; RCT, randomized controlled trial.

this intervention to reduce perioperative mortality? The authors did not include the possibility to "partially agree" with a statement; therefore, every answer refered to the full sentence. The option to answer "do not know" was included in the questionnaire to allow responders to state that they had no opinion or had never thought about that particular issue. Because methodologic research suggests, as previously mentioned, ${ }^{6,8}$ that there is no difference in response rate depending on the inclusion or exclusion of the "do not know" option (if less than 40\%), only the "yes" and "no" frequencies were reported in the results if not otherwise indicated.

After the second and last web vote, the interventions that reached less than $67 \%$ of agreement were considered as major exclusions (see Tables S1 and S2). The interventions with an impact on mortality that were approved after the web vote, with 
Table 2. Randomized Clinical Trials and Meta-Analyses of Randomized Clinical Trials Documenting a Mortality Reduction or an Increase in Mortality in the Postoperative Period

\begin{tabular}{|c|c|c|c|c|c|c|}
\hline Topics Improving Survival & First Author & Journal & Year & $\begin{array}{l}\text { RCT or META } \\
\text { of RCTs }\end{array}$ & $\begin{array}{l}\text { Number of Randomly } \\
\text { Assigned Patients }\end{array}$ & Country \\
\hline \multicolumn{7}{|l|}{ Increasing Survival } \\
\hline \multirow[t]{5}{*}{ Perioperative hemodynamic optimization } & Cecconi et al..$^{10}$ & Crit Care & 2013 & Meta-analysis & 315 & United Kingdom \\
\hline & Gurgel et al. ${ }^{11}$ & Anesth Analg & 2011 & Meta-analysis & 5,056 & Brazil \\
\hline & Hamilton et al. ${ }^{12}$ & Anesth Analg & 2011 & Meta-analysis & 4,805 & United Kingdom \\
\hline & Brienza et al. ${ }^{13}$ & Crit Care Med & 2009 & Meta-analysis & 4,220 & Italy \\
\hline & Poeze et al. ${ }^{14}$ & Crit Care Med & 2005 & Meta-analysis & 5,733 & Netherlands \\
\hline \multirow[t]{3}{*}{ Insulin for glycemic control } & Giakoumidakis et al. ${ }^{15}$ & Heart Lung & 2012 & $\mathrm{RCT}$ & 212 & Greece \\
\hline & Haga et al. ${ }^{16}$ & J Cardiothorac Surg & 2011 & Meta-analysis & 1,492 & United Kingdom \\
\hline & Van den Berghe et al. ${ }^{17}$ & N Engl J Med & 2001 & $\mathrm{RCT}$ & 1,548 & Belgium \\
\hline \multirow[t]{3}{*}{ Noninvasive ventilation } & Zhu et al. ${ }^{18}$ & Chin Med J & 2013 & $\mathrm{RCT}$ & 95 & China \\
\hline & Auriant et al. ${ }^{19}$ & Am J Respir Crit Care Med & 2001 & $\mathrm{RCT}$ & 48 & France \\
\hline & Antonelli et al. ${ }^{20}$ & JAMA & 2000 & $\mathrm{RCT}$ & 40 & Italy \\
\hline \multirow[t]{5}{*}{ Levosimendan } & Harrison et al. ${ }^{21}$ & J Cardiothorac Vasc Anesth & 2013 & Meta-analysis & 1,155 & United States \\
\hline & Landoni et al. ${ }^{22}$ & Crit Care Med & 2012 & Meta-analysis & 5,480 & Italy \\
\hline & Maharaj and Metaxa. ${ }^{23}$ & Crit Care & 2011 & Meta-analysis & 729 & United Kingdom \\
\hline & Landoni et al. ${ }^{24}$ & J Cardiothorac Vasc Anesth & 2010 & Meta-analysis & 440 & Italy \\
\hline & Levin et al. ${ }^{25}$ & Rev Esp Cardiol & 2008 & $\mathrm{RCT}$ & 137 & Argentina \\
\hline \multirow[t]{2}{*}{ Leuko-depleted red blood cell transfusion } & Bilgin et al. ${ }^{26}$ & Circulation & 2004 & $\mathrm{RCT}$ & 474 & Netherlands \\
\hline & Van de Watering et al. ${ }^{27}$ & Circulation & 1998 & $\mathrm{RCT}$ & 914 & Netherlands \\
\hline \multirow[t]{5}{*}{ Preoperative IABP in high-risk CABG } & Zangrillo et al. ${ }^{28}$ & Crit Care & 2015 & Meta-analysis & 625 & Italy \\
\hline & Sá et al. ${ }^{29}$ & Coron Artery Dis & 2012 & Meta-analysis & 345 & Brazil \\
\hline & Theologou et al. ${ }^{30}$ & Cochrane Database Syst Rev & 2011 & Meta-analysis & 255 & United Kingdom \\
\hline & Qiu et al. ${ }^{31}$ & J Cardiothorac Surg & 2009 & $\mathrm{RCT}$ & 221 & China \\
\hline & Dyub et al. ${ }^{32}$ & J Card Surg & 2008 & Meta-analysis & 2,363 & Canada \\
\hline \multirow[t]{2}{*}{ Volatile agents } & Landoni et al. ${ }^{33}$ & Br J Anaesth & 2013 & Meta-analysis & 3,642 & Italy \\
\hline & Landoni et al. ${ }^{34}$ & J Cardiothorac Vasc Anesth & 2007 & Meta-analysis & 1,922 & Italy \\
\hline Tranexamic acid & Ker et al. ${ }^{35}$ & BMJ & 2012 & Meta-analysis & 10,488 & United Kingdom \\
\hline \multirow[t]{4}{*}{ Neuraxial anesthesia } & Guay et al. ${ }^{36,37}$ & Anesth Analg, Cochrane Database Syst Rev & 2014 & Meta-analysis & 3,006 & Canada \\
\hline & Pöpping et al. ${ }^{38}$ & Ann Surg & 2014 & Meta-analysis & 2,201 & Germany \\
\hline & Rodgers et al. ${ }^{39}$ & $B M J$ & 2000 & Meta-analysis & 9,559 & New Zealand \\
\hline & Urwin et al..$^{40}$ & Br J Anaesth & 2000 & Meta-analysis & 1,578 & United Kingdom \\
\hline Remote ischemic preconditioning & Thielmann et al. ${ }^{41}$ & Lancet & 2013 & $\mathrm{RCT}$ & 329 & Germany \\
\hline $\begin{array}{l}\text { Selective decontamination of the } \\
\text { digestive tract }\end{array}$ & Nathens and Marshall. ${ }^{42}$ & Arch Surg & 1999 & Meta-analysis & Not available & Canada \\
\hline \multicolumn{7}{|l|}{ Increasing mortality } \\
\hline \multirow[t]{4}{*}{ Beta-blockers } & Wijeysundera et al. ${ }^{43,44}$ & Circulation, J Am Coll Cardiol & 2014 & Meta-analysis & 12,391 & Canada, United States \\
\hline & Blessberger et al. ${ }^{45}$ & Cochrane Database Syst Rev & 2014 & Meta-analysis & 19,211 & Austria \\
\hline & Devereaux et al. ${ }^{46}$ & Lancet & 2008 & $\mathrm{RCT}$ & 8,351 & Canada \\
\hline & Bouri et al. ${ }^{47}$ & Heart & 2014 & Meta-analysis & 10,529 & United Kingdom \\
\hline Aprotinin & Fergusson et al. ${ }^{48}$ & N Engl J Med & 2008 & $\mathrm{RCT}$ & 2,331 & Canada \\
\hline
\end{tabular}

Abbreviations: CABG, coronary artery bypass grafting; IABP, intra-aortic balloon pump; META, meta-analysis; RCT, randomized clinical trial. 
the references to the articles of RCTs or meta-analyses of RCTs supporting the evidence, are reported in Table 2 if overwhelming evidence was not published thereafter.

Throughout the process, all participants (either those voting via web or those participating in person) were asked to disclose all potential conflicts of interest. Analyses were repeated to include only answers without conflict of interests. There was no sponsor or industry support for this consensus conference.

Subanalyses were performed by country, to assess the relationship between the clinicians' opinion and the source of the evidence, and by the responders' specialty, to assess whether the approach to perioperative management differed among specialists in anesthesia and other healthcare professionals.

The gap between agreement and practice was measured by calculating the ratio of all the answers with consistency between agreement and use or avoidance in clinical practice over the total number of responses. Double votes were prevented by using the e-mail field as the unique identifier.

The ClinicalTrials.gov register for each intervention on the final list was surveyed to assess the current level of interest for testing each identified intervention.

\section{Statistical Analysis}

From the data provided in the articles, the relative risk reduction or increase, absolute risk reduction or increase, and number needed to treat or harm were calculated. The results of the web vote are expressed as percentage of positive votes. The percentage of agreement of the following data are reported: (1) selected literature; (2) use/avoidance in clinical practice; and (3) inclusion in future guidelines. Statistical analysis was performed using Stata 13 software (StataCorp, College Station, TX).

The chi-square or Fisher exact test was used to evaluate differences in percentages among countries and specialists. Statistical significance was set at $\mathrm{p}<0.05$.

\section{RESULTS}

Thirteen interventions were selected by 500 clinicians from 61 countries. The 13 interventions selected using the web survey were supported by 39 articles $^{10-48}$ (12 RCTs and 27 meta-analyses of RCTs). The following 11 interventions ${ }^{10-42}$ were reported to increase survival: perioperative hemodynamic optimization in high-risk surgical patients, neuraxial anesthesia compared with general anesthesia, noninvasive ventilation in acute respiratory failure, tranexamic acid, and selective decontamination of the gastrointestinal tract in critically ill patientsall in noncardiac surgery; insulin for tight glycemic control, preoperative intra-aortic balloon pump (IABP) in high-risk patients undergoing coronary artery bypass graft surgery, leuko-depleted red blood cells transfusion, levosimendan in patients with low ejection fraction, volatile agents, and remote ischemic preconditioning (RIPC) in patients undergoing coronary artery bypass graft surgery-all in cardiac surgery.

The 2 interventions found to increase mortality were the use of beta-blocker therapy in the immediate preoperative period of noncardiac surgery and the administration of aprotinin in cardiac surgery patients. ${ }^{4-48}$ The following countries included in the study had the highest number of voters: Australia, Italy, and the United Kingdom. Most participants were specialized in anesthesiology and intensive care (Table 3).

The articles were published between 1998 and 2015, with an increase in the number of articles in recent years and an increase in the studies' sample size (Fig 1). When focusing on RCTs, and therefore excluding meta-analyses of RCTs, a limited trend toward the number of patients included and in the number of centers included over the 16 years (1998-2013) were observed (Tables S3 and S4; Fig S1).

The journals that published the 39 articles with differences in mortality are reported in Table 4. The most frequent origins of the publishing authors were Canada, Italy, and the United Kingdom with 7 manuscripts each; authors from Canada, The Netherlands, and China published the highest number of RCTs (Table S5).

The percentages of agreement of the web voters with the previously identified interventions and their supporting statements ranged between $95 \%$ for perioperative hemodynamic optimization to $67 \%$ for selective decontamination of the digestive tract (see Table 1). The percentage of agreement among specialists of different countries was not statistically different for 8 of the 13 interventions, with the highest concordance seen for volatile agents (Table 5). There was no concordance in the other 5 of the 13 interventions (see Table 5). The consistency between agreement and practice varied from $79 \%$ for volatile agents to $35 \%$ for RIPC (Table 6).

The routine use of each drug/technique/strategy always was lower than the agreement for the same type of intervention. The less-used interventions were selective decontamination of the digestive tract $(15 \%)$ and remote ischemic preconditioning $(22 \%)$, and the most used were volatile agents (80\%) and preoperative hemodynamic optimization (74\%). Aprotinin was the most avoided intervention (78\%) and the only intervention in which clinical practice exceeded the agreement (Table 5). Statistically significant differences among represented countries in the use or avoidance of the interventions were observed for 8 of the 13 interventions (Table 5). When asked whether the interventions should be included in future guidelines, there was a general agreement above $67 \%$ for 10 interventions. Interestingly, opinions among the represented countries about the necessity of including interventions into future guidelines always were statistically significantly different for strategies

Table 3. Number of Voters from Each Country and Number of Anesthesiologist and/or Intensive Care Physicians Among Voters

\begin{tabular}{lcr}
\hline & Number of voters & Percentage \\
\hline Country & & \\
$\quad$ Australia & 56 & $11 \%$ \\
Italy & 50 & $10 \%$ \\
United Kingdom & 37 & $7 \%$ \\
Other Western countries & 170 & $34 \%$ \\
Other countries & 187 & $37 \%$ \\
$\quad$ Total & 500 & $100 \%$ \\
Profession & & \\
$\quad$ Anesthesiologist and/or intensive & 411 & $82 \%$ \\
$\quad$ care physician & & $18 \%$ \\
Others & 89 & $100 \%$ \\
$\quad$ Total & 500 & \\
\hline
\end{tabular}




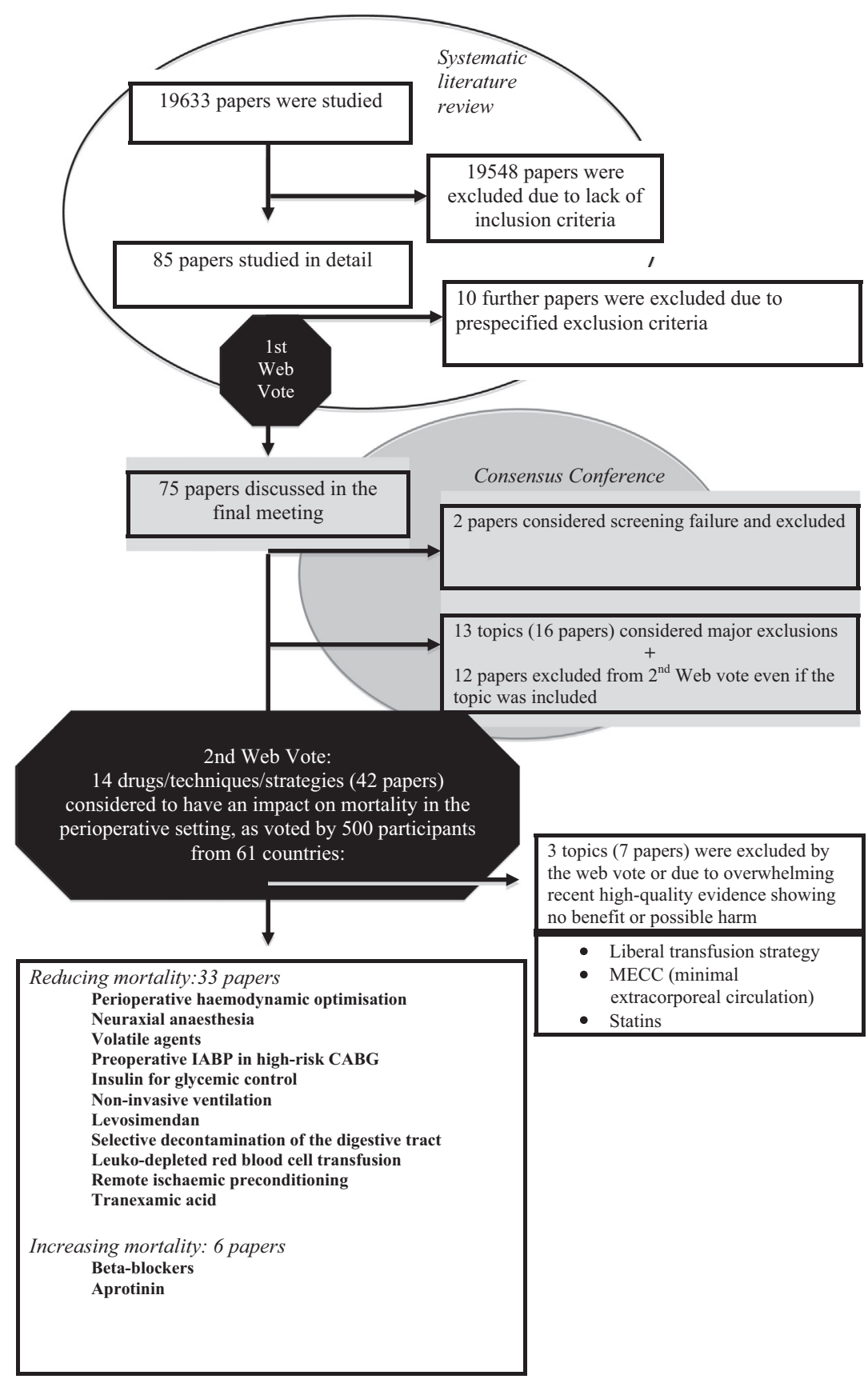

Fig 1. Flow chart on the web-based conference and selection of the interventions with an effect on mortality in the perioperative setting

increasing survival, whereas no difference was observed for interventions increasing mortality.

When comparing the opinions of anesthesiologists and intensive care specialists with other healthcare professionals about interventions reducing perioperative mortality, no statistically significant differences were observed. Conversely, for the interventions that might increase perioperative mortality (betablocker therapy and the use of aprotinin), intensive care specialists reported statistically significantly higher percentages of avoidance compared with other specialists (Table S6).
Declarations of a potential conflict of interest for each of the interventions ranged from $0 \%$ to $1.2 \%$, and the exclusion of these participants did not affect the results.

Several major study exclusions were identified and are reported in Tables S1 and S2, with the reason for exclusion. Notably, 2 interventions that reached the final stage of the web vote were excluded because they did not reach the minimum general agreement, set at $67 \%$. In fact, the percentage of agreement was $55 \%$ for liberal transfusion strategy and only $42 \%$ for minimal extracorporeal circulation. One intervention 
Table 4. Number of Articles Published by Each Journal

\begin{tabular}{lc}
\hline Journal & Number of Articles \\
\hline Anesth Analg & 3 \\
Circulation & 3 \\
Cochrane Database Syst Rev & 3 \\
Crit Care & 3 \\
Crit Care Med & 3 \\
J Cardiothorac Surg & 3 \\
J Cardiothorac Vasc Anesth & 3 \\
Br J Anaesth & 2 \\
BMJ & 2 \\
Lancet & 2 \\
$N$ Engl J Med & 2 \\
Am J Respir Crit Care Med & 1 \\
Ann Surg & 1 \\
Arch Surg & 1 \\
Chin Med J & 1 \\
Coron Artery Dis & 1 \\
Heart & 1 \\
Heart Lung & 1 \\
J Am Coll Cardiol & 1 \\
JAMA & 1 \\
Rev Esp Cardiol & 1 \\
\hline
\end{tabular}

(preoperative statin therapy in statin-naïve patients) ${ }^{49-51}$ was excluded after completion of the web vote because large, highquality RCTs showing no benefit and possible harm were published thereafter. $^{52,53}$

The list of the 132 ongoing trials identified on the ClinicalTrials.gov register for the 13 interventions is provided in Table S7, with different interests shown among the international community, ranging from 36 ongoing trials on perioperative tranexamic acid to no studies on aprotinin and leukodepleted red blood cells transfusion.

\section{DISCUSSION}

\section{Key Findings}

The authors identified all nonsurgical interventions (drugs, techniques, or strategies) that have been shown by at least 1 RCT or meta-analysis of RCTs to affect mortality significantly in the perioperative period of any adult surgery. Moreover, the authors analyzed how these interventions are regarded by a large cohort of colleagues worldwide and to what extent they translate into reported clinical practice. Through a well-proven "democratic" consensus process that has been described widely, ${ }^{4-8,54}$ the systematic review of literature was limited to the highest levels of evidence-based medicine (EBM) hierarchy and filtered through the views and experience of 500 clinicians from 61 countries. This is a unique feature of this consensus process, which allows physicians to directly provide their opinion on perioperative interventions associated with an increase or reduction in survival. In this way, the authors were able to determine the level of interest and perceived importance of these interventions. As such, it may become a pragmatic (patients') "survival guide" to be used by anesthesiologists, intensivists, and other specialists in their daily practice. Interestingly, the authors found differences among different countries and, only in a few cases, among different specialists.
Finally, this study provided the opportunity to analyze the existing gap between medical literature and clinical practice in the complex field of perioperative medicine. Furthermore, as an update of the consensus process conducted in $2011,{ }^{5}$ it allowed for an assessment of how rapidly EBM evolved, suggesting the need for continuous and quick updating (not only of literature, but also of industry beliefs) and for the conduct of high-quality RCTs focused on major outcomes such as mortality.

\section{Relationship to Previous Literature}

The present findings were of particular interest when compared with those of the first international web-based consensus process on perioperative mortality, which was held in 2011 and results of which were published in 2012. Although the number of interventions identified was almost the same, 3 of the 13 interventions that were included previously were excluded in the present update (chlorhexidine oral rinse, $\alpha_{2}$-adrenergic agonists, and perioperative supplemental oxygen), whereas 2 new interventions were included (tranexamic acid and RIPC). Chlorhexidine oral rinse and $\alpha_{2}$-adrenergic agonists were excluded due to the publication of subsequent studies not confirming a survival benefit ${ }^{55}$ or even reporting, in contrast to previous investigations, an increase in mortality. ${ }^{56}$ The presence of conflicting results of the 2 identified studies ${ }^{57,58}$ in addition to low agreement and the lack of a convincing underlying mechanism ${ }^{59,60}$ were the main reasons for the exclusion of perioperative supplemental oxygen.

Regarding the 2 new interventions included, additional corroborating evidence has become available for tranexamic acid, which previously was excluded due to the lack of clear evidence of a survival benefit in the perioperative period, and the only trial suggesting a reduction in mortality with RIPC $^{41}$ had not yet been published at the time of the first consensus process.

The authors also found an increased number of studies in support of a favorable effect on mortality for 6 of the 9 interventions that have been confirmed to improve survival: neuraxial anesthesia, volatile agents, insulin for glycemic control, noninvasive ventilation, levosimendan, and preoperative IABP. In particular, the number of supporting studies has risen dramatically (from 1 to 5) for the last 2 interventions.

Regarding interventions reducing survival, the number of supporting studies has increased greatly (from 1 to 4 ) for betablockers.

Another interesting comparison was with the similar consensus process conducted to identify interventions that can affect mortality in critically ill patients. ${ }^{7}$ The same therapeutic intervention can be beneficial in a clinical setting and harmful in another. In fact, both intensive insulin therapy and hemodynamic optimization (with supranormal oxygen delivery as a target) have been found possibly to be life-saving in the perioperative period and to potentially increase mortality in critically ill patients. Furthermore, intensive insulin therapy might be beneficial only among cardiac surgery patients but not among those undergoing noncardiac interventions, as suggested by the Normoglycaemia in Intensive Care Evaluation and Survival Using Glucose Algorithm Regulation (NICESUGAR) trial. ${ }^{61}$ 
Table 5. Percentages of Agreement and Use of the Interventions Identified as Increasing Survival or Mortality Overall and Divided by Countries

\begin{tabular}{|c|c|c|c|c|c|c|c|c|}
\hline Intervention & Question & Total & Australia & Italy & United Kingdom & Other Western Country & Other & $\mathrm{p}$ Value \\
\hline \multicolumn{9}{|l|}{ Increasing survival } \\
\hline \multirow[t]{3}{*}{ Perioperative hemodynamic optimization } & Agree & $95 \%$ & $85 \%$ & $98 \%$ & $94 \%$ & $94 \%$ & $98 \%$ & 0.001 \\
\hline & Use & $70 \%$ & $38 \%$ & $88 \%$ & $70 \%$ & $70 \%$ & $74 \%$ & $<0.001$ \\
\hline & Guidelines & $89 \%$ & $67 \%$ & $94 \%$ & $85 \%$ & $88 \%$ & $95 \%$ & $<0.001$ \\
\hline \multirow[t]{3}{*}{ Insulin for glycemic control } & Agree & $88 \%$ & $78 \%$ & $88 \%$ & $83 \%$ & $91 \%$ & $91 \%$ & 0.068 \\
\hline & Use & $66 \%$ & $49 \%$ & $70 \%$ & $66 \%$ & $64 \%$ & $71 \%$ & 0.061 \\
\hline & Guidelines & $76 \%$ & $57 \%$ & $74 \%$ & $65 \%$ & $74 \%$ & $86 \%$ & 0.001 \\
\hline \multirow[t]{3}{*}{ Noninvasive ventilation } & Agree & $88 \%$ & $95 \%$ & $98 \%$ & $95 \%$ & $85 \%$ & $85 \%$ & 0.047 \\
\hline & Use & $56 \%$ & $42 \%$ & $80 \%$ & $48 \%$ & $57 \%$ & $54 \%$ & 0.007 \\
\hline & Guidelines & $77 \%$ & $70 \%$ & $95 \%$ & $83 \%$ & $69 \%$ & $80 \%$ & 0.008 \\
\hline \multirow[t]{3}{*}{ Levosimendan } & Agree & $88 \%$ & $81 \%$ & $98 \%$ & $88 \%$ & $86 \%$ & $88 \%$ & 0.176 \\
\hline & Use & $41 \%$ & $13 \%$ & $82 \%$ & $16 \%$ & $42 \%$ & $40 \%$ & $<0.001$ \\
\hline & Guidelines & $67 \%$ & $39 \%$ & $86 \%$ & $67 \%$ & $62 \%$ & $73 \%$ & 0.001 \\
\hline \multirow[t]{3}{*}{ Leuko-depleted red blood cell transfusion } & Agree & $86 \%$ & $76 \%$ & $84 \%$ & $95 \%$ & $87 \%$ & $89 \%$ & 0.220 \\
\hline & Use & $52 \%$ & $66 \%$ & $39 \%$ & $29 \%$ & $63 \%$ & $45 \%$ & 0.001 \\
\hline & Guidelines & $77 \%$ & $68 \%$ & $65 \%$ & $70 \%$ & $75 \%$ & $85 \%$ & 0.037 \\
\hline \multirow[t]{3}{*}{ Preoperative IABP in high-risk $C A B G$} & Agree & $85 \%$ & $73 \%$ & $98 \%$ & $88 \%$ & $78 \%$ & $90 \%$ & 0.001 \\
\hline & Use & $46 \%$ & $22 \%$ & $71 \%$ & $57 \%$ & $37 \%$ & $51 \%$ & $<0.001$ \\
\hline & Guidelines & $69 \%$ & $45 \%$ & $88 \%$ & $70 \%$ & $54 \%$ & $82 \%$ & 0.000 \\
\hline \multirow[t]{3}{*}{ Volatile agents } & Agree & $85 \%$ & $88 \%$ & $87 \%$ & $83 \%$ & $84 \%$ & $84 \%$ & 0.965 \\
\hline & Use & $76 \%$ & $75 \%$ & $67 \%$ & $65 \%$ & $76 \%$ & $80 \%$ & 0.357 \\
\hline & Guidelines & $75 \%$ & $58 \%$ & $84 \%$ & $71 \%$ & $70 \%$ & $82 \%$ & 0.019 \\
\hline \multirow[t]{3}{*}{ Tranexamic acid } & Agree & $84 \%$ & $82 \%$ & $86 \%$ & $84 \%$ & $86 \%$ & $80 \%$ & 0.746 \\
\hline & Use & $65 \%$ & $39 \%$ & $65 \%$ & $65 \%$ & $74 \%$ & $66 \%$ & $<0.001$ \\
\hline & Guidelines & $65 \%$ & $39 \%$ & $65 \%$ & $65 \%$ & $74 \%$ & $66 \%$ & 0.011 \\
\hline \multirow[t]{3}{*}{ Neuraxial anesthesia } & Agree & $81 \%$ & $75 \%$ & $89 \%$ & $69 \%$ & $79 \%$ & $84 \%$ & 0.123 \\
\hline & Use & $65 \%$ & $46 \%$ & $60 \%$ & $60 \%$ & $70 \%$ & $70 \%$ & 0.021 \\
\hline & Guidelines & $74 \%$ & $57 \%$ & $72 \%$ & $64 \%$ & $74 \%$ & $82 \%$ & 0.012 \\
\hline \multirow[t]{3}{*}{ Remote ischemic preconditioning } & Agree & $80 \%$ & $90 \%$ & $75 \%$ & $81 \%$ & $76 \%$ & $83 \%$ & 0.333 \\
\hline & Use & $12 \%$ & $0 \%$ & $13 \%$ & $0 \%$ & $6 \%$ & $22 \%$ & $<0.001$ \\
\hline & Guidelines & $47 \%$ & $22 \%$ & $52 \%$ & $56 \%$ & $37 \%$ & $61 \%$ & 0.001 \\
\hline \multirow[t]{3}{*}{ Decontamination of the digestive tract } & Agree & $67 \%$ & $61 \%$ & $82 \%$ & $72 \%$ & $68 \%$ & $62 \%$ & 0.136 \\
\hline & Use & $14 \%$ & $4 \%$ & $22 \%$ & $10 \%$ & $16 \%$ & $15 \%$ & 0.142 \\
\hline & Guidelines & $45 \%$ & $31 \%$ & $54 \%$ & $65 \%$ & $40 \%$ & $46 \%$ & 0.045 \\
\hline \multicolumn{9}{|l|}{ Increasing mortality } \\
\hline \multirow[t]{3}{*}{ Beta-blockers } & Agree & $83 \%$ & $88 \%$ & $76 \%$ & $83 \%$ & $89 \%$ & $78 \%$ & 0.055 \\
\hline & Avoid & $57 \%$ & $57 \%$ & $59 \%$ & $56 \%$ & $65 \%$ & $49 \%$ & 0.087 \\
\hline & Guidelines & $70 \%$ & $61 \%$ & $80 \%$ & $66 \%$ & $70 \%$ & $71 \%$ & 0.386 \\
\hline \multirow[t]{3}{*}{ Aprotinin } & Agree & $73 \%$ & $87 \%$ & $94 \%$ & $44 \%$ & $70 \%$ & $69 \%$ & $<0.001$ \\
\hline & Avoid & $77 \%$ & $71 \%$ & $65 \%$ & $52 \%$ & $84 \%$ & $78 \%$ & 0.010 \\
\hline & Guidelines & $67 \%$ & $74 \%$ & $65 \%$ & $59 \%$ & $64 \%$ & $69 \%$ & 0.733 \\
\hline
\end{tabular}

NOTE. Agree: Do you agree with the above sentence? Use/Avoid: Do you routinely use/avoid this intervention in your clinical practice? Guidelines: Would you include this intervention into future international guidelines to reduce perioperative mortality?/Would you suggest that future international guidelines should contraindicate this intervention to reduce perioperative mortality?

Abbreviations: $C A B G$, coronary artery bypass grafting; IABP, intra-aortic balloon pump.

\section{Implications for Clinical Practice}

Although mortality after elective surgery is relatively low, ${ }^{1,62}$ even a small improvement in survival may translate into thousands of lives saved each year, given the enormous number of surgical procedures performed worldwide. Physicians treating surgical patients make everyday decisions on which anesthetic techniques to apply, drugs to administer (or avoid), and other nonsurgical strategies to use, often without knowing whether those decisions actually affect mortality in their patients. Guidelines can provide helpful information about interventions that may influence mortality but also include recommendations on many other aspects and therefore are often dispersive, usually focused on a certain type of patient or surgery, and have some limitations, including not always strictly adhering to EBM. ${ }^{54}$ Through this consensus methodology, for the first time to authors' knowledge, all interventions for which there was sufficient, nonconflicting, and widely agreed-upon evidence of an impact on perioperative mortality in any adult surgical setting are listed together.

Despite the fact that the percentage of agreement was above $80 \%$ for most of the interventions improving survival, the consistency between agreement and use in clinical practice often was much lower; the same was true for the lessexpensive, widely available, and easy-to-perform interventions. These findings may boost research on interventions with a high level of agreement and therefore should be considered priority 
Table 6. Percentage of Consistency Between Agreement and Practice for Each Intervention Increasing Survival (1-11) and Increasing Mortality (12-13)

\begin{tabular}{lc}
\hline Intervention & Percentage Concordance \\
\hline 1. Volatile agents & $79 \%$ \\
2. Tranexamic acid & $75 \%$ \\
3. Perioperative hemodynamic optimization & $73 \%$ \\
4. Insulin for glycemic control & $73 \%$ \\
5. Neuraxial anesthesia & $71 \%$ \\
6. Noninvasive ventilation & $67 \%$ \\
7. Preoperative IABP in high-risk CABG & $63 \%$ \\
8. Leuko-depleted red blood cell transfusion & $62 \%$ \\
9. Levosimendan & $56 \%$ \\
10. Selective decontamination of the digestive & $48 \%$ \\
tract & \\
11. Remote ischemic preconditioning & $35 \%$ \\
12. Aprotinin & $75 \%$ \\
13. Beta-blockers & $71 \%$ \\
\hline
\end{tabular}

Abbreviations: $C A B G$, coronary artery bypass grafting; IABP, intraaortic balloon pump.

to determine without doubt whether they are beneficial and therefore increase their widespread use.

Overall, however, the percentage of agreement and the consistency with both clinical use and the potential inclusion into international guidelines suggested that EBM remains the ideal benchmark of clinical practice, although greater efforts should be made to remove or mitigate those factors (eg, ingrained beliefs, "academic" traditions, discordant hints from guidelines and opinion leaders, or simply the time needed by physicians to digest recently published evidence) that prevent clinical practice from readily adapting to the evolving evidence. In this regard, the intervention of liberal transfusion strategy, the most interesting major exclusion (Tables $\mathrm{S} 1$ and $\mathrm{S} 2$ ), is emblematic. Although it was one of the topics with the highest level of evidence ( 3 recent RCTs found a reduced mortality in the perioperative setting with liberal transfusion strategies), it has been excluded due to low agreement among web voters. Along with the novelty of the message, this probably was due to the existence of guidelines recommending exactly the opposite. Notably, a recent meta-analysis ${ }^{63}$ confirmed that EBM was in favor of a liberal transfusion strategy in surgical patients, and the results of the Transfusion Requirements in Cardiac Surgery (TRICS) III trial ${ }^{64}$ hopefully will provide clearer insights about this topic.

\section{New Evidence}

The body of biomedical literature is growing, and new evidence on critical interventions is produced continuously. As a consequence, additional evidence in support of a given intervention has become available since the last web vote. In particular, recent meta-analyses reported a survival benefit associated with the use of volatile agents in cardiac (but not in noncardiac) surgery ${ }^{65}$; perioperative hemodynamic optimization $^{66}$ and preoperative IABP $^{67}$ also were associated with benefits.

In contrast, although RIPC was included among interventions that may reduce mortality, 2 multicenter RCTs published by the New England Journal of Medicine in the time interval between the consensus and the writing of this manuscript demonstrated that RIPC had no effect on clinically relevant outcomes, ${ }^{68,69}$ even if there still was the possibility that the use of propofol in this setting may impair the beneficial effects of RIPC. This "pendulum effect," however, is part of the nature of EBM. ${ }^{70}$

Importantly, recent trials on preoperative statin therapy in statin-naïve patients offered another example of rapidly changing evidence. Even though statin therapy was associated with reductions in mortality in some older RCTs and a meta-analysis of RCTs, ${ }^{49-51} 2$ large RCTs published after the consensus vote demonstrated not only that statins did not reduce mortality but may instead increase the risk of developing acute kidney injury in cardiac surgery patients. ${ }^{52,53}$ The authors of this study therefore decided to exclude this intervention from those associated with mortality reduction.

In addition to recently published evidence, ongoing studies hopefully will provide definitive answers on several interventions. Three large, multicenter RCTs on levosimendan use in cardiac surgery currently are ongoing, ${ }^{71,72}$ and a large trial on tranexamic acid use in coronary artery surgery (ATACAS trial) recently has been completed. ${ }^{73}$ In addition, the authors identified 132 studies registered as "currently recruiting" on ClinicalTrials.gov on these 13 topics.

\section{Strengths and Limitations}

The main strength of this study was that it combined EBM with a unique methodology, which allowed the authors to investigate the real views and the therapeutic approaches of clinicians worldwide. The analysis of consistency between agreement and use/avoidance showed that reported clinical practice often adapts slowly to evidence and emphasized the need to rethink the paths that lead from literature to clinical practice. The reason for this discrepancy between agreement and use/avoidances patterns was not investigated and was a limitation of this study. Nevertheless, this finding provided an interesting area for future investigation.

Conversely, the comparison with the previous consensus process, of which this study represented an update, clearly showed how fast evidence evolves. Furthermore, evidence now is stronger for most of the previously included interventions, and this may promote their implementation into clinical practice.

Another strength of this study was the comparison of web voters' responses among different countries, which demonstrated that healthcare probably is less "global" than it is perceived to be. In particular, the opinions about the need to include the interventions in future guidelines always were significantly different among different countries. This may reflect, for example, a different attitude toward medico-legal issues or different local cultures. Unfortunately, the reason for such differences among countries was not investigated.

The rapid change of evidence also was a limitation of this study, as reflected by the new evidence on some of the interventions (eg, RIPC, statins) that has become available since the final web vote. Lack of definitive evidence on different interventions has been acknowledged during the consensus conference and led to position statements that could be classified as conditional sentences ("may reduce") and 
highlighted the need for further investigations. The authors decided to keep their survey as simple as possible by providing only 3 possible answers to the statements (agree, not agree, do not know). Although this might be a limitation, it nevertheless allowed the authors to determine which topics physicians all over the world considered to be supported by the strongest evidence as more important and therefore should be implemented most easily, should a definitive trial be performed. When developing the survey, the authors did not separate the possibility to agree with the effect of the intervention on mortality from the possibility to agree with the need for further investigation, and the authors acknowledge that this was a limitation of this study. Nevertheless, it is difficult to believe that someone who agrees that a certain intervention may save lives would not be willing to test the same intervention to obtain definitive evidence.

Other limitations were shared with the previous consensus process and included the scarcity of randomized research in the perioperative setting, the possibility that many other interventions showing favorable effects on important outcomes other than mortality may be of similar value on survival, and the lack of any detail (definitions, doses, timing, odds ratios, confidence intervals, to name but a few) about the included interventions, which are only listed and very briefly contextualized. However, a textbook recently was dedicated to the detailed discussion of all the interventions included in the previous consensus process, ${ }^{74}$ and a second edition detailing the updated interventions is underway.

\section{CONCLUSIONS}

This updated international web-based consensus conference process identified 13 interventions supported by randomized evidence suggesting their role in reducing or increasing perioperative mortality in adults undergoing any surgical intervention. Moreover, the analysis of web voting confirmed that there is a gap between evidence and clinical practice and that both the perception of medical literature and the clinical conduct of physicians are significantly different among countries for many of the included interventions. Future research and funding should better define the role of these interventions and major exclusions and should investigate the possible means to reduce both the gap existing between evidence and clinical practice and the differences among various countries. It is desirable that at least the most robust among the identified interventions be discussed soon in international guidelines on perioperative mortality reduction.

\section{ACKNOWLEDGMENTS}

We thank Maieutics Foundation for sharing the technical expertise for the voting process.

\section{APPENDIX A. SUPPLEMENTARY MATERIAL}

Supplementary data are available in the online version of this article at http://dx.doi.org/10.1053/j.jvca.2016.07.017

\section{REFERENCES}

1. Pearse RM, Moreno RP, Bauer P, et al; European Surgical Outcomes Study (EuSOS) group for the trials groups of the European Society of Intensive Care Medicine and the European Society of Anaesthesiology: Mortality after surgery in Europe: A 7 day cohort study. Lancet 380:1059-1065, 2012

2. Devereaux PJ, Xavier D, Pogue J, et al: Characteristics and short-term prognosis of perioperative myocardial infarction in patients undergoing noncardiac surgery: A cohort study. Ann Intern Med 154: 523-528, 2011

3. Weiser TG, Regenbogen SE, Thompson KD, et al: An estimation of the global volume of surgery: A modelling strategy based on available data. Lancet 372:139-144, 2008

4. Landoni G, Augoustides JG, Guarracino F, et al: Mortality reduction in cardiac anaesthesia and intensive care: Results of the first International Consensus Conference. Acta Anaesthesiol Scand 55:259-266, 2011

5. Landoni G, Rodseth RN, Santini F, et al: Randomised evidence for reduction of perioperative mortality. J Cardiothorac Vasc Anesth 26:764-772, 2012

6. Landoni G, Bove T, Székely A, et al: Reducing mortality in acute kidney injury patients: Systematic review and international web-based survey. J Cardiothorac Vasc Anesth 27:1384-1398, 2013

7. Landoni G, Comis M, Conte M, et al: Mortality in multicenter critical care trials: An analysis of interventions with a significant effect. Crit Care Med 43:1559-1568, 2015

8. Pisano A, Landoni G, Lomivorotov V, et al: Worldwide opinion on multicenter randomized interventions showing mortality reduction in critically ill patients: A democracy-based medicine approach. J Cardiothorac Vasc Anesth 43:1559-1568, 2015

9. Van Es JC, Lawrence DP, Morgan GW, et al: Don't know responses in environmental surveys. J Environ Educ 27:13-18, 1996
10. Cecconi M, Corredor C, Arulkumaran N, et al: Clinical review: Goal-directed therapy-what is the evidence in surgical patients? The effect on different risk groups. Crit Care 17:209, 2013

11. Gurgel ST, do Nascimento P Jr: Maintaining tissue perfusion in high-risk surgical patients: A systematic review of randomised clinical trials. Anesth Analg 112:1384-1391, 2011

12. Hamilton MA, Cecconi M, Rhodes A: A systematic review and meta-analysis on the use of preemptive haemodynamic intervention to improve postoperative outcomes in moderate and high-risk surgical patients. Anesth Analg 112:1392-1402, 2011

13. Brienza N, Giglio MT, Marucci M, et al: Does perioperative hemodynamic optimization protect renal function in surgical patients? A meta-analytic study. Crit Care Med 37:2079-2090, 2009

14. Poeze M, Greve JW, Ramsay G: Meta-analysis of hemodynamic optimization: Relationship to methodological quality. Crit Care 9: R771-R779, 2005

15. Giakoumidakis K, Eltheni R, Patelarou E, et al: Effects of intensive glycemic control on outcomes of cardiac surgery. Heart Lung 42:146-151, 2013

16. Haga KK, McClymont KL, Clarke S, et al: The effect of tight glycaemic control, during and after cardiac surgery, on patient mortality and morbidity: A systematic review and meta-analysis. J Cardiothorac Surg 6:3, 2011

17. Van den Berghe G, Wouters P, Weekers F, et al: Intensive insulin therapy in critically ill patients. N Engl J Med 345:1359-1367, 2011

18. Zhu GF, Wang DJ, Liu S, et al: Efficacy and safety of non invasive positive pressure ventilation in the treatment of acute respiratory failure after cardiac surgery. Chin Med J 126:4463-4469, 2013 
19. Auriant I, Jallot A, Hervé P, et al: Non invasive ventilation reduces mortality in acute respiratory failure following lung resection. Am J Respir Crit Care Med 164:1231-1235, 2001

20. Antonelli M, Conti G, Bufi M, et al: Noninvasive ventilation for treatment of acute respiratory failure in patients undergoing solid organ transplantation: A randomized trial. JAMA 283:235-241, 2000

21. Harrison RW, Hasselblad V, Mehta RH, et al: Effect of levosimendan on survival and adverse events after cardiac surgery: A meta-analysis. J Cardiothorac Vasc Anesth 27:1224-1232, 2013

22. Landoni G, Biondi-Zoccai G, Greco M, et al: Effects of levosimendan on mortality and hospitalization. A meta-analysis of randomised controlled studies. Crit Care Med 40:634-646, 2012

23. Maharaj R, Metaxa V: Levosimendan and mortality after coronary revascularization: A meta-analysis of randomized controlled trials. Crit Care 15:R140, 2011

24. Landoni G, Mizzi A, Biondi-Zoccai G, et al: Reducing mortality in cardiac surgery with levosimendan: A meta-analysis of randomised controlled trials. J Cardiothorac Vasc Anesth 24:51-57, 2010

25. Levin RL, Degrange MA, Porcile R, et al: The calcium sensitizer levosimendan gives superior results to dobutamine in postoperative low cardiac output syndrome. Rev Esp Cardiol 61:471-479, 2008

26. Bilgin YM, Van de Watering LM, Eijsman L, et al: Doubleblind, randomised controlled trial on the effect of leukocyte-depleted erythrocyte transfusions in cardiac valve surgery. Circulation 109: 2755-2760, 2004

27. Van de Watering LM, Hermans J, Houbiers JG, et al: Beneficial effects of leukocyte depletion of transfused blood on postoperative complications in patients undergoing cardiac surgery: A randomised clinical trial. Circulation 97:562-568, 1998

28. Zangrillo A, Pappalardo F, Dossi R, et al: Preoperative intraaortic balloon pump to reduce mortality in coronary artery bypass graft: A meta-analysis of randomized controlled trials. Crit Care 19:10, 2015

29. Sá MP, Ferraz PE, Escobar RR, et al: Prophylactic intra-aortic balloon pump in high-risk patients undergoing coronary artery bypass surgery: A meta-analysis of randomised controlled trials. Coron Artery Dis 23:480-486, 2012

30. Theologou T, Bashir M, Rengarajan A, et al: Preoperative intra aortic balloon pumps in patients undergoing coronary artery bypass grafting. Cochrane Database Syst Rev 19:CD004472, 2011

31. Qiu Z, Chen X, Xu M, et al: Evaluation of preoperative intraaortic balloon pump in coronary patients with severe left ventricular dysfunction undergoing OPCAB surgery: Early and mid-term outcomes. J Cardiothorac Surg 4:39, 2009

32. Dyub AM, Whitlock RP, Abouzahr LL, et al: Preoperative intraaortic balloon pump in patients undergoing coronary bypass surgery: A systematic review and meta-analysis. J Card Surg 23:79-86, 2008

33. Landoni G, Greco T, Biondi-Zoccai G, et al: Anaesthetic drugs and survival: A Bayesian network meta-analysis of randomised trials in cardiac surgery. Br J Anaesth 111:886-896, 2013

34. Landoni G, Biondi-Zoccai GG, Zangrillo A, et al: Desflurane and sevoflurane in cardiac surgery: A meta-analysis of randomised clinical trials. J Cardiothorac Vasc Anesth 21:502-511, 2007

35. Ker K, Edwards P, Perel P, et al: Effect of tranexamic acid on surgical bleeding: Systematic review and cumulative meta-analysis. BMJ 344:e3054, 2012

36. Guay J, Choi PT, Suresh S, et al: Neuraxial anesthesia for the prevention of postoperative mortality and major morbidity: An overview of Cochrane systematic reviews. Anesth Analg 119:716-725, 2014

37. Guay J, Choi P, Suresh S, et al: Neuraxial blockade for the prevention of postoperative mortality and major morbidity: An overview of Cochrane systematic reviews. Cochrane Database Syst Rev 1: CD010108, 2014

38. Pöpping DM, Elia N, Van Aken HK, et al: Impact of epidural analgesia on mortality and morbidity after surgery: Systematic review and meta-analysis of randomised controlled trials. Ann Surg 259: 1056-1067, 2014

39. Rodgers A, Walker N, Schug S, et al: Reduction of postoperative mortality and morbidity with epidural or spinal anaesthesia: Results from overview of randomised trials. BMJ 321:1493, 2000

40. Urwin SC, Parker MJ, Griffiths R: General versus regional anaesthesia for hip fracture surgery: A meta-analysis of randomized trials. Br J Anaesth 84:450-455, 2000

41. Thielmann M, Kottenberg E, Kleinbongard P, et al: Cardioprotective and prognostic effects of remote ischaemic preconditioning in patients undergoing coronary artery bypass surgery: A single-centre randomised, double-blind, controlled trial. Lancet 382:597-604, 2013

42. Nathens AB, Marshall JC: Selective decontamination of the digestive tract in surgical patients: A systematic review of the evidence. Arch Surg 134:170-176, 1999

43. Wijeysundera DN, Duncan D, Nkonde-Price C, et al: Perioperative beta blockade in noncardiac surgery: A systematic review for the 2014 ACC/AHA Guideline on Perioperative Cardiovascular Evaluation and Management of Patients Undergoing Noncardiac Surgery: A Report of the American College of Cardiology/American Heart Association Task Force on Practice Guidelines. Circulation 130: 2246-2264, 2014

44. Wijeysundera DN, Duncan D, Nkonde-Price C, et al: Perioperative beta blockade in noncardiac surgery: A systematic review for the 2014 ACC/AHA Guideline on Perioperative Cardiovascular Evaluation and Management of Patients Undergoing Noncardiac Surgery: A Report of the American College of Cardiology/American Heart Association Task Force on Practice Guidelines. J Am Coll Cardiol 64: 2406-2425, 2014

45. Blessberger H, Kammler J, Domanovits H, et al: Perioperative beta-blockers for preventing surgery-related mortality and morbidity. Cochrane Database Syst Rev 9:CD004476, 2014

46. Devereaux PJ, Yang H, Yusuf S, et al: Effects of extendedrelease metoprolol succinate in patients undergoing non-cardiac surgery (POISE trial): A randomised controlled trial. Lancet 371:1839-1847, 2008

47. Bouri S, Shun-Shin MJ, Cole GD, et al: Meta-analysis of secure randomised controlled trials of $\beta$-blockade to prevent perioperative death in non-cardiac surgery. Heart 100:456-464, 2014

48. Fergusson DA, Hébert PC, Mazer CD, et al: A comparison of aprotinin and lysine analogues in high-risk cardiac surgery. $\mathrm{N}$ Engl J Med 358:2319-2331, 2008

49. De Waal BA, Buise MP, Van Zundert AA: Perioperative statin therapy in patients at high risk for cardiovascular morbidity undergoing surgery: A review. Br J Anaesth 114:44-52, 2015

50. Kobashigawa JA, Moriguchi JD, Laks H, et al: Ten-year followup of a randomised trial of pravastatin in heart transplant patients. J Heart Lung Transplant 24:1736-1740, 2005

51. Schouten O, Boersma E, Hoeks SE, et al: Fluvastatin and perioperative events in patients undergoing vascular surgery. $\mathrm{N}$ Engl J Med 361:980-989, 2009

52. Zheng Z, Jayaram R, Jiang L, et al: Perioperative rosuvastatin in cardiac surgery. N Engl J Med 374:1744-1753, 2016

53. Billings FT 4th, Hendricks PA, Schildcrout JS, et al: High-dose perioperative atorvastatin and acute kidney injury following cardiac surgery: A randomized clinical trial. JAMA 315:877-888, 2016

54. Greco M, Zangrillo A, Mucchetti $M$, et al: Democracybased consensus in medicine. J Cardiothorac Vasc Anesth 29:506-509, 2015

55. Klompas M, Speck K, Howell MD, et al: Reappraisal of routine oral care with chlorhexidine gluconate for patients receiving mechanical ventilation: Systematic review and meta-analysis. JAMA Intern Med 174:751-761, 2014 
56. Price HI, Agnew MD, Gamble JM: Comparative cardiovascular morbidity and mortality in patients taking different insulin regimens for type 2 diabetes: A systematic review. BMJ Open 5:e006341, 2015

57. Brar MS, Brar SS, Dixon E: Perioperative supplemental oxygen in colorectal patients: A meta-analysis. J Surg Res 166: 227-235, 2011

58. Meyhoff CS, Jorgensen LN, Wetterslev J, et al: Increased longterm mortality after a high perioperative inspiratory oxygen fraction during abdominal surgery: Follow-up of a randomised clinical trial. Anesth Analg 115:849-854, 2012

59. Pisano A: Perioperative supplemental oxygen to reduce surgical site infection: Too easy to be true. J Trauma Acute Care Surg 76:1332, 2014

60. Pisano A, Capasso A: Perioperative supplemental oxygen to reduce perioperative mortality, in Landoni G, Ruggeri L, Zangrillo A (eds). Reducing mortality In the perioperative period. Cham, Switzerland, Springer, 2014, pp. 77-83

61. Finfer S, Chittock DR, Su SY, et al: Intensive versus conventional glucose control in critically ill patients. N Engl J Med 360: 1283-1297, 2009

62. Kristensen SD, Knuuti J, Saraste A, et al: 2014 ESC/ESA Guidelines on non-cardiac surgery: Cardiovascular assessment and management: The Joint Task Force on non-cardiac surgery: Cardiovascular assessment and management of the European Society of Cardiology (ESC) and the European Society of Anaesthesiology (ESA). Eur Heart J 35:2383-2431, 2014

63. Fominskiy E, Putzu A, Monaco F, et al: Liberal transfusion strategy improves survival in perioperative but not in critically ill patients. A meta-analysis of randomised trials. $\mathrm{Br} \mathrm{J}$ Anaesth 115: 511-519, 2015

64. Murphy GJ, Pike K, Rogers CA: Liberal or restrictive transfusion after cardiac surgery. N Engl J Med, 372:997-1008, 2015
65. Uhlig C, Bluth T, Schwarz K, et al: Effects of volatile anesthetics on mortality and postoperative pulmonary and other complications in patients undergoing surgery: A systematic review and meta-analysis. Anesthesiology 124:1230-1245, 2016

66. Giglio M, Manca F, Dalfino L, et al: Perioperative haemodynamic goal-directed therapy and mortality: Systematic review and meta-analysis with meta regression. Minerva Anestesiol [epub ahead of print].

67. Pilarczyk K, Boening A, Jakob H, et al: Preoperative intra-aortic counterpulsation in high-risk patients undergoing cardiac surgery: A meta-analysis of randomized controlled trials. Eur J Cardiothorac Surg 49:5-17, 2016

68. Hausenloy DJ, Candilio L, Evans R, et al: Remote ischemic preconditioning and outcomes of cardiac surgery. N Engl J Med 373: 1408-1417, 2015

69. Meybohm P, Bein B, Brosteanu O, et al: A multicenter trial of remote ischaemic preconditioning for heart surgery. N Engl J Med 373: 1397-1407, 2015

70. Vincent JL: We should abandon randomized controlled trials in the intensive care unit. Crit Care Med 38:S534-S538, 2010

71. Toller W, Heringlake M, Guarracino F, et al: Preoperative and perioperative use of levosimendan in cardiac surgery: European expert opinion. Int J Cardiol 184:323-336, 2015

72. Zangrillo A, Alvaro G, Pisano A, et al: A randomized controlled trial of levosimendan to reduce mortality in high-risk cardiac surgery patients (CHEETAH): Rationale and design. Am Heart J 177: 66-73, 2016

73. Myles PS, Smith J, Knight J, et al: Aspirin and Tranexamic Acid for Coronary Artery Surgery (ATACAS) Trial: Rationale and design. Am Heart J 155:224-230, 2008

74. Landoni G, Ruggeri L, Zangrillo A: Reducing mortality in the perioperative period. Cham, Switzerland: Springer, 2014 